\section{Transgenic Resistance to the Colorado Potato Beetle in Bt-expressing Eggplant Fields}

\author{
Nazareno Acciarri and Gabriele Vitelli \\ Istituto Sperimentale Orticoltura, I-63030 Monsampolo del Tronto (AP), Italy \\ Salvatore Arpaia \\ Metapontum Agrobios, S.S. 106 Km. 448.2 I-75010 Metaponto (MT), Italy
}

Giuseppe Mennella

Istituto Sperimentale Orticoltura, P.O. BOX 48 I-84098 Pontecagnano (SA), Italy

Francesco Sunseri ${ }^{1}$

Dipartimento Biologia, Difesa, Biotecnologie AgroForestali, Università della Basilicata I-85100 Potenza, Italy

Giuseppe L. Rotino

Istituto Sperimentale Orticoltura, Via Paullese 28 I-26836 Montanaso L. (LO), Italy

Additional index words. Solanum melongena, Leptinotarsa decemlineata, fruit production, DAS-ELISA analysis, sustainable pest control management

\begin{abstract}
Colorado potato beetle (CPB; Leptinotarsa decemlineata-Say) is a serious pest because it has developed resistance against insecticides. Three transgenic eggplant (Solanum melongena L.) lines bearing a mutagenized Bacillus thuringiensis Berl. gene coding for the Cry3B toxin, and the nontransformed control DR2-line were tested in field trials to assess their insect resistance. The transgenic lines 3-2, 6-1, and 9-8 were tested at two different locations in a randomized complete-block design. Samples were taken biweekly to assess the level of CPB and the presence of other insects. At harvest, total yield and fruit number per plot were recorded. Two transgenic lines showed high levels of resistance at both locations, as measured by CPB abundance and yield. Fruit production was almost twice as great in the highly resistant lines (3-2 and 9-8) as in the nontransformed control. The 6-1 transgenic line showed an intermediate level of resistance; it was similar to the control under heavy $C P B$ pressure and was comparable to the other transgenic lines under milder infestations. Analysis by double antibody sandwich-enzyme linked immunosorbent assay (DAS-ELISA), performed on different tissues, revealed a lower amount of Cry3B protein in the 6-1 transgenic line than in lines 3-2 and 9-8. No detrimental effects on nontarget arthropods (including the chrysomelid Altica) were evident. Field observations confirmed that Bt may be able to control CPB infestation in eggplant, representing a potential effective and environmentally safe means of pest control.
\end{abstract}

Resistance in eggplant to Colorado potato beetle (CPB) is critical for production in America and Europe due to heavy damage (Arpaia et al., 1995; Hamilton et al., 1997). In Italy, cultivation of early potato (the preferred

Received for publication 19 Mar. 1999. Accepted for publication 5 Nov. 1999. This research was made possible by a grant from Italian Ministry for Agricultural Politics in the framework of the 'Progetto Finalizzato Orticoltura'. We thank A. Giannantonio, B. Ricchiuto, G. Sabino, G.M. Di Leo, and M. Mancini for their helpful collaboration with the field experiments. The cost of publishing this paper was defrayed in part by the payment of page charges. Under postal regulations, this paper therefore must be hereby marked advertisement solely to indicate this fact.

${ }^{1}$ To whom reprint requests should be addressed. E-mail address: sunseri@unibas.it effects on insect predators feeding on transgenic pollen (Pilcher et al., 1997a).

Transgenic crops expressing Bt-derived toxins are effective in controlling insect populations (e.g., Benedict et al., 1996; Hamilton et al., 1997; Jansen et al., 1997). The use of transgenic plants engineered for insect resistance were the topic of $24 \%$ of all requests for field release of genetically modified organisms approved or acknowledged by the U.S. Dept. of Agriculture (USDA) through Jan. 1998, and represents the second most common transgene.

The use of transgenic resistant cultivars of horticultural crops could be an important alternative means of pest control. Transgenic eggplants resistant to $\mathrm{CPB}$ by expression of $\mathrm{Bt}$ Cry3 genes (Arpaia et al., 1997; Hamilton et al., 1997; Iannacone et al., 1997; Jelenkovic et al., 1998) may represent a new and effective means of pest control. Resistant lines should be nontoxic to nontarget organisms (including mammals) and environmentally safe. The objective of this study was to evaluate transgenic eggplant lines expressing a modified Bt gene under natural CPB infestation for their yield performance and insect resistance.

\section{Materials and Methods}

Plants. Transgenic eggplant lines were obtained by selfing parental transformed plants from line DR2 (Arpaia et al., 1997) and were used for field experiments. Kanamycinresistant plants were self-pollinated and screened by spraying with a kanamycin solution (Sunseri et al., 1993). Segregation analysis, chi square, and $P$ values on selfed progenies of the transgenic lines and the nontransformed control were obtained, indicating the number of nonlinked transgenes. Kanamycin-resistant plants were used in field experiments.

Experimental fields. Fields were prepared in a randomized complete-block design with four replications, at two different locations: Metaponto (MT-Italy) and Monsampolo del Tronto (AP-Italy) with the approval of the Italian Ministry of Public Health (No. B/IT/ 97-05A). Transgenic eggplant lines 3-2, 6-1, and 9-8 and the nontransformed control DR2 were planted and natural infestation was used to evaluate resistance. The plants were transplanted on 25 May 1997 at Monsampolo and on 23 June 1997 at Metaponto. Eggplants were mulched, planted in double rows at a density of 2.2 plants $/ \mathrm{m}^{2}$, and cultivated following the traditional cultural practices of each location (e.g., La Malfa, 1990; Panero, 1981). Each plot measured $4.5 \times 9.6 \mathrm{~m}$ and contained 96 plants.

Field observations. Data were collected twice a week beginning 3 weeks after transplanting. Ten percent of the plants in each replication were randomly chosen for visual inspection and the numbers of CPB adults, egg masses, small and large larvae on each plant were recorded. At Metaponto, field data on the presence of other insects in the canopy were also collected. Surveys were carried out for 7 and 10 weeks at Metaponto and 
Monsampolo fields, respectively. At each harvest, fruit number and weight were recorded. Plants were harvested seven times between July and Sept. 1997.

Cry3B toxin quantification. In the field trial at Monsampolo, during the growing season, Cry3B protein levels were quantified by double antibody sandwich-enzyme linked immunosorbent assay (DAS-ELISA) analyses (Arpaia et al., 1997) using different tissues of transgenic eggplants; young and old leaf, fruit, and flower. The dilution ratio for fruit and flower samples was 1:3 (w/v) in extraction buffer. Four plants were randomly sampled from each replication in July and Sept. 1997.

Statistical analyses. Insect abundance and yields were analyzed as a randomized complete-block design with repeated measures. DAS-ELISA values were analyzed as a completely randomized design of analysis of variance (ANOVA). Means were compared by least significant difference (LSD). All the analyses were performed by using SAS software, version 6.12 for Windows (SAS Inst., 1989).

\section{Results and Discussion}

The selection of the offspring bearing the transgene either in homozygous or heterozygous state were performed as described in Sunseri et al. (1993). The data, collected after in vivo spray test and analyzed by chi-square test, suggested the presence and the expression of one (lines 3-2 and 9-8) or two copies (line 6-1) of the transgene (Table 1). More- over, since the transgenic line 6-1 showed an intermediate level of insect resistance, both in insect bioassays and DAS-ELISA tests, a gene silencing phenomenon may be present (Dieguez et al., 1998; Stam et al., 1997).

At Monsampolo, the beetle population was sizeable and apparently completed two generations. Initially, the population was probably from overwintering beetles. At the beginning of July and in the second half of August, the number of egg masses peaked, especially in the 9-8 line (July) and the DR2 control line (August). While incoming beetles spread quite evenly on all plots, small and large larvae were found mainly on lines DR2 (control) and 6-1, and this trend led to a higher number of adults on the same eggplant lines toward the end of the season (Figs. 1-2). Beetle populations (expressed as number of egg masses and larvae per plant) were significantly higher on the control line DR2 than on the transgenic lines (Table 2). Among the latter, 9-8 showed the lightest attack; the other two transgenic lines had comparable numbers of egg masses, but a smaller per- centage of eggs developed into larvae. The average number of eggs per egg mass on eggplant has been reported to be from 26 to 30 (Jansson et al., 1989). Survival values of $10 \%$ to $11.5 \%$ and $13.7 \%$ to $15.8 \%$ were observed on the lines 3-2 and 6-1, respectively, vs. $29 \%$ to $34.1 \%$ on DR2 and $5.1 \%$ to $5.9 \%$ on $9-8$. Line $6-1$ was intermediate between the nontransformed control and the other two transgenic lines for average number of larvae per plant.

In the field trial at Metaponto, the attack by CPB started from one edge of the field near where a potato crop had been harvested 3 weeks before. The first block was more severely damaged than the other blocks (data not shown). Because of the late planting date, incoming beetles were mostly first generation adults. The infestation level was not high throughout the season. Therefore, pooled numbers of small and large larvae represented the level of infestation. Adults appeared evenly distributed among different eggplant lines and only toward the end of the growing season did the average number per

Table 1. Segregation ratios, chi-square values and $P$ values for kanamycin resistance in $S_{1}$ families transgenic eggplant progenies.

\begin{tabular}{lcrrccc}
\hline Family & No. plants tested & $\mathrm{KmR}^{\mathrm{z}}$ & $\mathrm{KmS}^{\mathrm{y}}$ & Ratio $(\mathrm{KmR} / \mathrm{KmS})$ & $\chi^{2}$ value & $P$ value \\
\hline $3-2^{\mathrm{x}}$ & 945 & 675 & 270 & $3: 1$ & 6.430 & 0.01 \\
$6-1^{\mathrm{x}}$ & 1140 & 1078 & 62 & $15: 1$ & 1.281 & 0.26 \\
$9-8^{\mathrm{x}}$ & 965 & 730 & 235 & $3: 1$ & 0.214 & 0.64 \\
DR2 & 970 & 0 & 970 & --- & --- & --- \\
\hline
\end{tabular}

${ }^{\mathrm{z}} \mathrm{KmR}$, kanamycin-resistant.

${ }^{\mathrm{y}} \mathrm{KmS}$, kanamycin-sensitive.

${ }^{x}$ Self-pollinated.
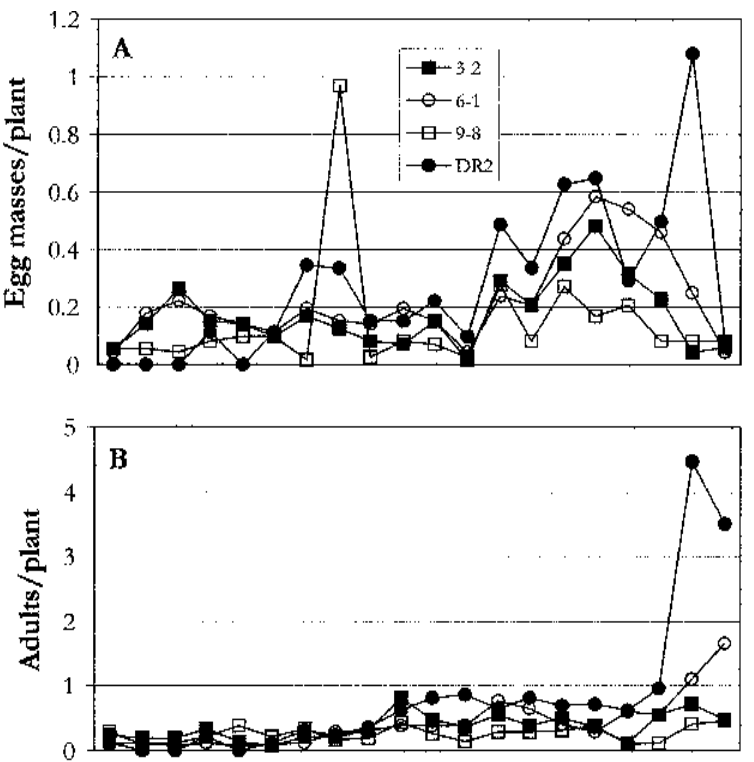

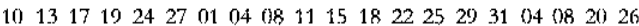
Jur Jul Aurs

Sampling time

Fig. 1. Colorado potato beetle infestation course at Monsampolo field trial in 1997: egg masses and adults per plant.
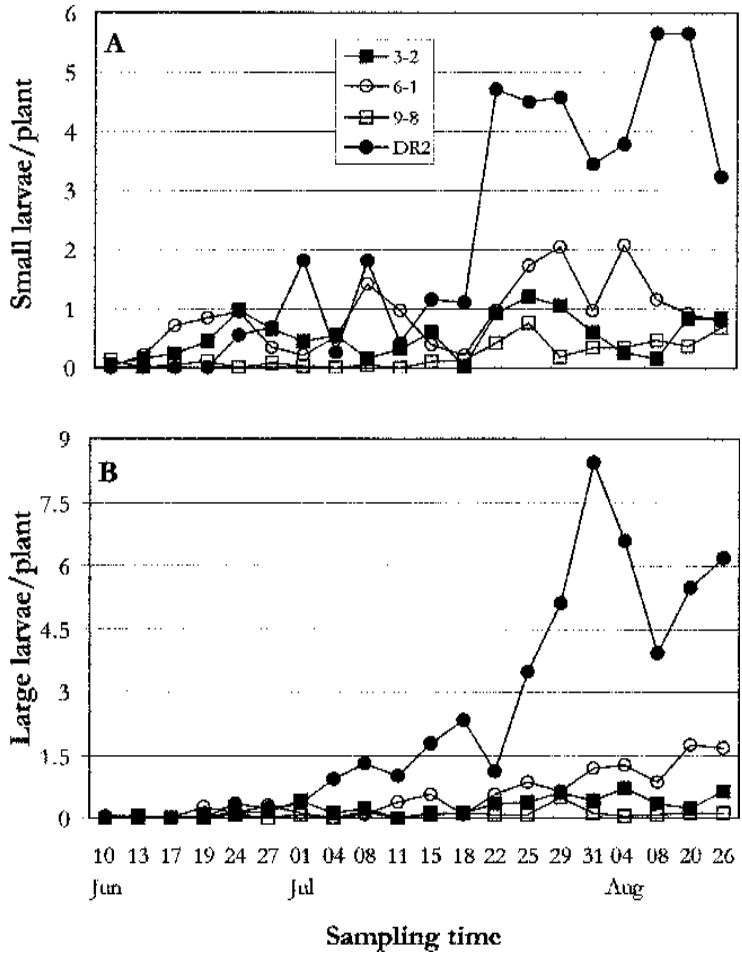

Fig. 2. Colorado potato beetle infestation course at Monsampolo field trial in 1997: small and large larvae per plant. 
plant reach two in the control plots (Fig. 3). Lines 6-1 and DR2 initially had higher numbers of egg masses, while toward the end of the growing season the numbers were higher on control plants (Fig. 3). Considering the egg masses laid, the percentage of small larvae surviving were $8.3 \% \pm 1.3 \%, 3.6 \% \pm$ $0.9 \%, 0.7 \% \pm 0.1 \%$, and $8.9 \% \pm 1.7 \%$ on the lines 3-1, 6-1, 9-8, and DR2, respectively. Nevertheless, the numbers of both egg masses and larvae were significantly higher on the nontransformed DR2 line (Table 2).

The numbers of the insects most commonly found in the Metaponto field trial are

Table 2. Mean number of Colorado potato beetle egg masses, larvae per plant, and eggplant fruit production in field experiments conducted at Monsampolo and Metaponto, Italy, in 1997.

\begin{tabular}{lcccr}
\hline \hline & & & \multicolumn{2}{c}{ Yield per plant } \\
\cline { 4 - 5 } Line & No. egg masses/plant & No. larvae/plant & & No. fruit \\
\hline & & Monsampolo & \\
$3-2$ & $0.13 \mathrm{~b}^{2}$ & $0.21 \mathrm{c}$ & $1.30 \mathrm{a}$ & $6.23 \mathrm{a}$ \\
$6-1$ & $0.17 \mathrm{~b}$ & $0.45 \mathrm{~b}$ & $0.58 \mathrm{bc}$ & $3.48 \mathrm{~b}$ \\
$9-8$ & $0.08 \mathrm{c}$ & $0.07 \mathrm{c}$ & $0.98 \mathrm{ab}$ & $6.18 \mathrm{a}$ \\
DR2 & $0.21 \mathrm{a}$ & $1.91 \mathrm{a}$ & $0.40 \mathrm{c}$ & $2.75 \mathrm{a}$ \\
& & Metaponto & & \\
$3-2$ & $0.03 \mathrm{~b}$ & $0.05 \mathrm{~b}$ & $0.94 \mathrm{a}$ & $8.47 \mathrm{a}$ \\
$6-1$ & $0.07 \mathrm{a}$ & $0.08 \mathrm{~b}$ & $1.01 \mathrm{a}$ & $9.34 \mathrm{a}$ \\
$9-8$ & $0.02 \mathrm{~b}$ & $0.03 \mathrm{~b}$ & $1.06 \mathrm{a}$ & $10.06 \mathrm{a}$ \\
DR2 & $0.09 \mathrm{a}$ & $0.21 \mathrm{a}$ & $0.43 \mathrm{~b}$ & $4.18 \mathrm{~b}$ \\
\hline
\end{tabular}

${ }^{2}$ Mean separation within columns and parameters by LSD, $P=0.05$.
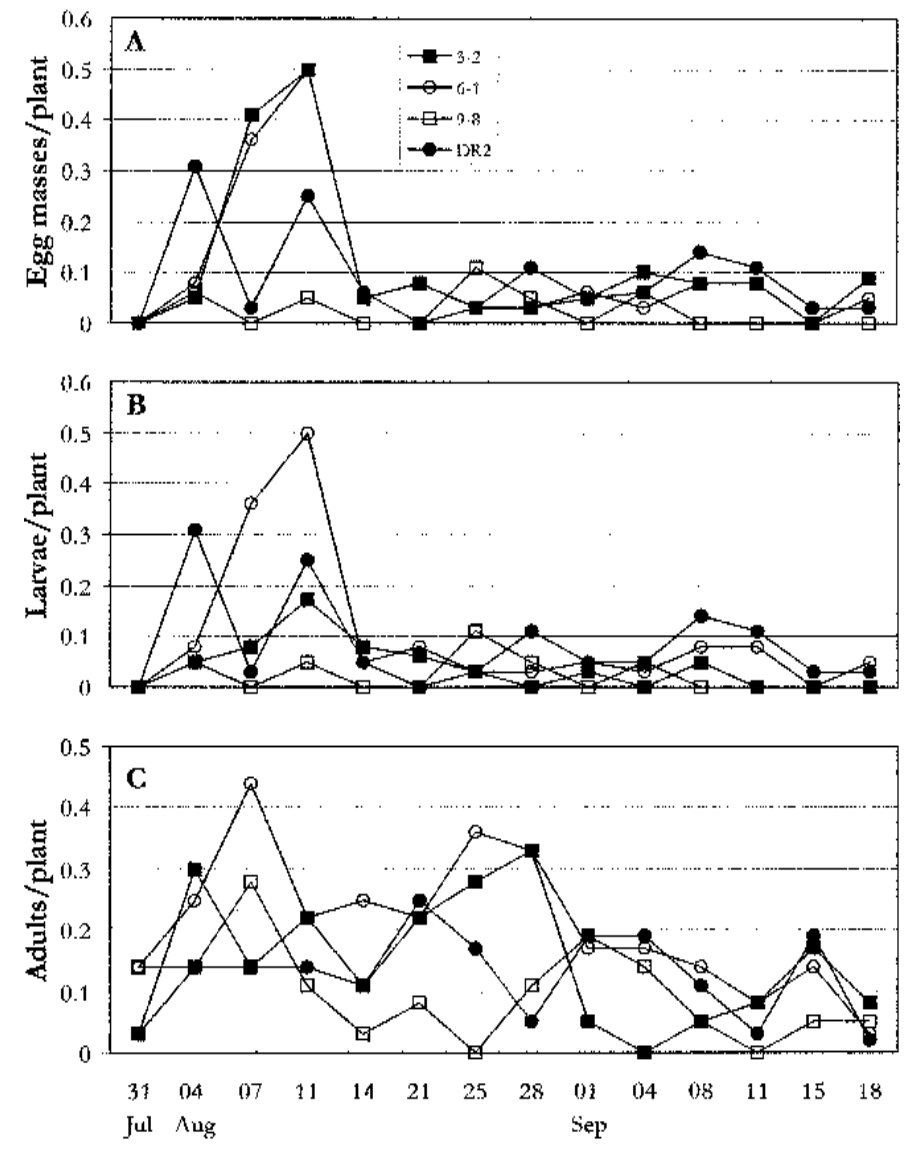

Sampling time

Fig. 3. Colorado potato beetle infestation course at Metaponto field trial in 1997. Data relative to small and large larvae have been pooled. beetle (Altica sp.) was apparently not affected by the presence of Cry3B toxin. The maximum number of leaves damaged by the beetle was $80 \%$ in most of the plants, but was higher in transgenic lines (Table 3 ), perhaps because of the better vegetative growth achieved by transgenic clones, allowing them to withstand $\mathrm{CPB}$ attack. Phthorimaea operculella larvae caused damage on berries. Surprisingly, the control line suffered significantly more damage $(P>0.019)$ than did the transgenic lines (Table 3 ).

ELISA showed that the transgenic line 61 had a lower amount of Bt toxin than did lines 3-2 and 9-8 (Table 4). In particular, the leaf and fruit tissues of line 6-1 contained significantly lower levels of Bt toxin than did corresponding tissues of lines 3-2 and 9-8 (young leaf: $P>0.0001$; old leaf: $P>0.0073$; fruit: $P>0.0002)$. Bt toxin content in lines 3 2 and 9-8 did not differ significantly.

Fruit production was about twice as great in transgenic lines than in the DR2 control (Table 2), largely because of the higher number of fruits produced per plant. Differences were more pronounced at Monsampolo, where $\mathrm{CPB}$ infestation was greater. Yields of line 6-1 were intermediate and, under mild infestation, tended to be similar to those of the other transgenic lines; however, under high pressure by L. decemlineata, production did not differ significantly from that of the DR2 control line. These results are in agreement with the surveys of CPB larvae in the lines tested, whose feeding activity drastically reduced the canopy in the nontransformed line. Although the Bt gene was in the heterozygous or homozygous state, no visual differences in the response to CPB was noted among plants within each transgenic line.

These preliminary field experiments clearly indicate that the resistance to CPB in eggplant expressing the Cry3B protein is expressed under field conditions. Moreover, transgenic plots had lower populations of all CPB stages and higher yields, even at strong infestation levels. The resistance of line 6-1 was intermediate between the other two transgenic lines and the nontransformed control.

The development of flea beetles, which are taxonomically close to $\mathrm{CPB}$, was apparently not impaired on transgenic eggplants, indicating a specific effect of resistance. Further studies should be conducted to confirm the different sensitivities of two chrysomelids to the Cry3B protein. The extent of fruit damage by $P$. operculella seems to indicate an activity of Cry3B toxin on Lepidoptera. This implies that a larger range of insect resistance may exist for these eggplant lines. Also, in this case, field observations over several years are of paramount importance for germplasm evaluation. No evidence of detrimental effects on other arthropods [e.g., aphids (Myzus percicae Sulz.), lacewings (Chrysoperla carnea Stephens)] were found.

The two most effective transgenic lines have been used to produce eggplant hybrids that are now in field trials to gather more accurate information on their possible commercial use. 
Table 3. Mean numbers of nontarget insects collected at Metaponto, Italy, in 1997.

\begin{tabular}{lcccc}
\hline \hline Line & $\begin{array}{c}\text { No. } \\
\text { C. } \text { carnea/plant }^{\mathrm{z}}\end{array}$ & $\begin{array}{c}\text { No. aphid } \\
\text { colonies/plant }\end{array}$ & $\begin{array}{c}\text { No. leaves damaged } \\
\text { by Altica } \text { sp./plant }\end{array}$ & $\begin{array}{c}\text { No. fruits damaged by } \\
\text { P. } \text { operculella/plant }^{\mathrm{x}}\end{array}$ \\
\hline DR2 & $0.02 \mathrm{a}^{\mathrm{w}}$ & $0.01 \mathrm{a}$ & $5.23 \mathrm{~b}$ & $7.72 \mathrm{a}$ \\
$\#$ 3-2 & $0.01 \mathrm{a}$ & $0.01 \mathrm{a}$ & $5.65 \mathrm{ab}$ & $4.47 \mathrm{~b}$ \\
$\#$ 6-1 & $0.02 \mathrm{a}$ & $0.03 \mathrm{a}$ & $6.06 \mathrm{a}$ & $4.98 \mathrm{~b}$ \\
$\#$ 9-8 & $0.01 \mathrm{a}$ & $0.01 \mathrm{a}$ & $6.19 \mathrm{a}$ & $5.17 \mathrm{~b}$ \\
\hline
\end{tabular}

${ }^{\mathrm{z}}$ Larvae + eggs.

${ }^{y}$ Average of three samplings during the month of August.

${ }^{\mathrm{x}}$ Average of all harvests.

${ }^{\text {w}}$ Mean separation within columns and parameters by LSD, $P \leq 0.05$.

Table 4. Mean DAS-ELISA $\left(\mathrm{OD}_{\text {ratio }}\right)^{\mathrm{z}}$ results for eggplant lines carrying the Cry3B protein.

\begin{tabular}{lccccc}
\hline \hline Line & Mean & Young leaf & Old leaf & Flower & Fruit \\
\hline $9-8$ & $6.81 \mathrm{a}^{\mathrm{y}}$ & $6.87 \mathrm{a}$ & $6.47 \mathrm{a}$ & $5.38 \mathrm{a}$ & $8.52 \mathrm{a}$ \\
$3-2$ & $6.19 \mathrm{a}$ & $6.60 \mathrm{a}$ & $6.10 \mathrm{a}$ & $5.65 \mathrm{a}$ & $6.40 \mathrm{a}$ \\
$6-1$ & $3.42 \mathrm{~b}$ & $2.70 \mathrm{~b}$ & $4.10 \mathrm{~b}$ & $5.20 \mathrm{a}$ & $1.67 \mathrm{~b}$
\end{tabular}

${ }^{2} \mathrm{OD}_{\text {ratio }}$ represents the ratio of absorbance values of transformed plants to those of on transformed plants at $492 \mathrm{~nm}$.

${ }^{\mathrm{y}}$ Mean separation within columns and parameters by LSD, $P \leq 0.05$.

\section{Literature Cited}

Arpaia, S., J.H. Lashomb, and K. Vail. 1995. Valutazione dell'attività trofica di Leptinotarsa decemlineata (Say) su melanzana. Inf. Fitopat. 2:55-57.

Arpaia, S., G. Mennella, V. Onofaro, E. Perri, F. Sunseri, and G.L. Rotino. 1997. Production of transgenic eggplant (Solanum melongena L.) resistant to Colorado potato beetle (Leptinotarsa decemlineata Say). Theor. Appl. Genet. 95:329-334

Benedict, J.H., E.S. Sachs, D.W. Altman, W.R. Deaton, R.J. Kohel, D.R. Ring, and S.A. Berberich. 1996. Field performance of cottons expressing transgenic Cry1A insecticidal proteins for resistance to Heliothis virescens and Helicoverpa zea (Lepidoptera: Noctuidae). J. Econ. Entomol. 89:230-238.

Dieguez, M.J., H. Vaucheret, J. Paszkowski, and O.M. Scheid. 1998. Cytosine methylation at CG and CNG sites is not a prerequisite for the initiation of transcriptional gene silencing in plants, but it is required for its maintenance Mol. Gen. Genet. 259:207-215.

Dogan, E.B., R.E. Berry, G.L. Reed, and P.A.
Rossignol. 1996. Biological parameters of convergent lady beetle (Coleoptera: Coccinellidae) feeding on aphids (Homoptera: Aphididae) on transgenic potato. J. Econ. Entomol. 89:11051108.

Hamilton, G.C., G.L. Jelenkovic, J.H. Lashomb, G. Ghidiu, S. Billings, and J.M. Patt. 1997. Effectiveness of transgenic eggplant (Solanum melongena L.) against the Colorado potato beetle. Adv. Hort. Sci. 11:189-192.

Hardee, D.D. and W.W. Bryan 1997. Influence of Bacillus thuringiensis-transgenic and nectarless cotton on insect populations with emphasis on the tarnished plant bug (Heteroptera: Miridae). J. Econ. Entomol. 90:663-668.

Iannacone, R., P.D. Grieco, and F. Cellini. 1997. Specific sequence modifications of a cry3B endotoxin gene result in high levels of expression and insect resistance. Plant Mol. Biol. 34:485-496.

Jansen, S., A. van Vliet, C. Dickburt, L. Buysse, C. Piens, B. Saey, A. De Wulf, V. Gosselé, A. Paez, E. Gobel, and M. Peferoen. 1997. Transgenic corn expressing a Cry9C insecticidal protein from Bacillus thuringiensis protected from European corn borer damage. Crop
Sci. 37:1616-1624.

Jansson R. K., Zitzman A. E., and J. H. Lashomb 1989. Effects of food plant and diapause on adult survival and fecundity of Colorado potato beetle (Coleoptera: Chrysomelidae). Environ. Entomol. 18:291-297.

Jelenkovic, G., S. Billings, Q. Chen, J. Lashomb, G. Hamilton, and G. Ghidiu. 1998. Transformation of eggplant with synthetic cryIIIA gene produces a high level of resistance to the Colorado potato beetle. J. Amer. Soc. Hort. Sci. 123:19-25.

Johnson, M.T. 1997. Interaction of resistant plants and wasp parasitoids of tobacco budworm (Lepidoptera: noctuidae). Envir. Entomol. 26:207-214.

La Malfa, G. 1990. Melanzana (Solanum melongena L.), p. 793-810. In V. Bianco, F. Pimpini (eds.). Orticoltura. Patron Editore.

Orr, D.B. and D.A. Landis. 1997. Oviposition of European corn borer (Lepidoptera: Pyralidae) and impact of natural enemy populations in transgenic versus isogenic corn. J. Econ. Entomol. 90:905-909.

Panero, M. 1981. Peperone e Melanzana. La tecnica di coltivazione e la difesa antiparassitaria, $\mathrm{p}$. 109-203. Editore REDA, Bologna.

Pilcher, C.D., J.J. Obrycki, M.E. Rice, and L.C. Lewis. 1997a. Preimaginal development, survival, and field abundance of insect predators on transgenic Bacillus thuringiensis corn. Envir. Entomol. 26:446-454.

Pilcher, C.D., M.E. Rice, J.J. Obrycki, and L.C. Lewis. 1997b. Field and laboratory evaluations of transgenic Bacillus thuringiensis corn on secondary lepidopteran pests (Lepidoptera: Noctuidae). J. Econ. Entomol. 90:669-678.

SAS Institute. 1989. SAS/STAT user's guide. Version 6, Fourth edition, Vol. 2. SAS Inst., Cary, N.C.

Stam, M., J.N.M. Mol, and J.M. Kooter. 1997. The silence of genes in transgenic plants. Ann. Bot. 79:3-12.

Sunseri, F., M.C. Fiore, F. Mastrovito, E. Tramontano, and G.L. Rotino. 1993. In vivo selection and genetic analysis for kanamycin resistance in transgenic eggplant (Solanum melongena L.). J. Genet. Breed. 47:299-306.

Wagner, D.L., J.W. Peacock, J.L. Carter, and S.E. Talley. 1996. Field assessment of Bacillus thuringiensis on nontarget Lepidoptera. Environ. Entomol. 25:1444-1454. 